\section{LOCAL ANALGESIA: BRACHIAL PLEXUS}

By R. R. Macintoch, M.A., D.M., F.R.C.S. 3rd Edition. Pp. 62, with 32 illustrations. Edinburgh: E. \& S. Livingstone Ltd. 1954. ros. $6 \mathrm{~d}$.

Only minor alterations and additions !have been made in the 3 rd edition of this well-known monograph.

The section on analgesia has been largely rewritten, with the inclusion of lignocaine, to bring it up to date.

A new plate showing the stellate ganglion and its connections, and a fuller account of pneumothorax as a complication of brachial plexus block, enhance the value of this excellent little book.

\section{THE BRITISH JOURNAL OF ANAESTHESIA}

Joint Editors: E. Falkner Hill and T. Cecil GraY.

'The British Journal of Anaesthesia,' which was published on alternate months, commenced monthly issues on January $\mathrm{I}, 1955$.

In anaesthesia the British lead the world and the regular publication of this journal will help to increase that lead. The growth of anaesthesia as a specialty has been spectacular and there is as yet no sign that this rate of growth is slowing down. We therefore welcome the extra numbers of this journal.

The subscription rate is to be $£ 3$ I $5 \mathrm{~s}$. od. inland and $£_{4} 4 \mathrm{~s}$. od. overseas.

\section{REVIEW OF MEDICAL MICROBIOLOGY}

By Ernest Jawetz, Ph.D., M.D., Joseph L. Melnick, Ph.D., and Edward A. Adelberg, Ph.D. Pp. 360. Los Altos: Lange Medical Publications. 1954. \$4.50.

This is a new publication intended to be the first of a series; other volumes will follow every two years. There have been no good general summaries of the advances in microbiology published since the war, although readers with specialized knowledge have been well supplied by the various year books. This first volume has been relatively cheaply produced with a limp cover and with the illustrations printed in the text. It is surprising how well even the electron micrographs stand up to the treatment and this is a tribute both to the judgment exercised in their selection and the technical excellence of the original material.

The subject-matter is probably more elementary than it will be in subsequent volumes and this appears sound policy since many medical workers have lost touch with this field and cannot easily bring themselves up to date without a quick revision course in the elementary work. It is for this reason that a concise description of bacteria and viruses and their classification is included and the whole of the necessary medical mycology has been compressed into about twenty pages without any loss; this section is a masterly example of lucid condensation.

The stresses are clearly medical and predominantly clinical. There are few details of technique, but instead there are brief descriptions of those methods on which new knowledge hase been based, as in the excellent chapters on genetics? and mutation. The clear indications for the tests in various virus diseases will be most useful. As might be expected from these writers the sections on chemotherapy are particularly fully dealt with.

The contents of the book would make a perfectly satisfactory senior course for medical students and there is enough material to meet the reference needs of postgraduates in any branches except microbiology itself. Controversial issues are avoided and the presentation is not particularly biased in favour of American work. While the principles are applicable in this country the actual methods of testing milks, waters, etc., are different, but this is unlikely to be misleading. It can be unbesitatingly recommended.

\section{CLINICAL PSYCHIATRY}

By W. MAYER-Gross, M.D.,. F.R.C.P., Ellot SlATER, M.A., M.D., F.R.C.P., D.P.M., and Martin Roth, M.D., M.R.C.P. Pp. xx + 652 . London: Cassell \& Co. Ltd. 1954. 5os.

In view of the spate of text-books on psychiatry which have appeared since the end of the warand their increasing cost-the potential buyer will naturally wish to know why some are to be recommended in preference to others. The assets of this present volume are self-evident; in size and scope it is all-embracing, while the fact its authors are 
among the 'lions' of psychiatry is sufficient evidence of the authority and experience which they bring to their work.

This is a fully-fledged exposition of a somewhat difficult subject, written for the consultant psychiatrist as much as for the potential diplomate in psychological medicine, and designed to become a constant source of reference in mental hospital and psychiatric clinic.

A notable exclusion from the text is the lengthy case history usually included to illustrate each type of mental illness. This is definitely a progressive step, for much of the bulk of contemporary works is taken up with such histories, which are either common place to the psychiatrist or else of no more than historic interest. Even the D.P.M. student does not require this type of exemplification, for the rules which govern his course of study ensure that by protracted residence in mental hospitals he will have adequate familiarity with the real thing.

The gap thus left has been filled with subjects which often receive little more than a bare mention. The legal and administrative aspects of insanity are dealt with in a very comprehensive manner, and much of the space devoted to this particular branch of psychiatry describes the procedures in use in other countries. To some these notes will be merely of interest, but to those in sympathy with the wider biosocial implications of preventive detention and restraint, there is much food for thought. Another noteworthy accent has been placed on ageing and its problems, problems which are becoming more and more acute as the lifespan is increased-and applicable as much to mental inpatients as to those in the outside world. General, social and psychological aspects of old age are skilfully welded into the study of the mental diseases of the aged, and this chapter makes a very real contribution to social medicine.

Child psychiatry occupies an adequate space in a work of this type. The child psychiatrist will naturally look for books devoted exclusively to this subject, but for the consultant seeing the occasional child in an adult clinic, there is plenty of good advice and general direction. This chapter reflects, too, the general bias of the book as a whole.

This is essentially a scientific treatise; the authors are men interested in medicine as a science, as their long record of medical research bears out, and no theory or hypothesis finds their favour unless supported by adequate clinical evidence and scientific fact. This is a most laudable approach, although many will feel that the omission of 'many " working hypotheses' derived from the psycho-analytic schools leaves the psychiatrist's armamentarium unnecessárily weak if not unpleasantly empty. No one will disagree, however, that the attitude of the authors is commendable. In providing a clean cut scientific approach to psychiatry they have cleared away much of the fog which has for many years tended to obscure the issue. This book, in other words, can be read with confidence that every statement derives from clinical experience and systematic observation. Between its covers will be found no fancy theories that risk complete refutation in a few years time, and there can be little doubt that this will rank as a standard textbook in psychiatry for many years to come.

$$
\text { L.R.C.H. }
$$

\section{MODERN TRENDS IN PSYCHOSOMATIC MEDICINE}

By Desmond O'Neill. Pp. xi +384 , illustrated. London: Butterworth \& Co. 1955. 55s.

Readers of previous volumes have come to expect an exceptionally high standard in the "Modern Trend' series, and they will not be disappointed in the latest addition. Though old in concept, psychosomatic medicine is very young in realisation, and like many new fields of progress tends to contain a large number of extremists, who range from the purely organic to the purely psychological adherents. With the increasing popularity, a misuse of terms and concepts is occuring to a misleading degree, and some formulation and delineation of the subject has long been needed; these needs are ably met in the first two chapters.

The structure of medical training is such, that the graduate emerges with a rather vague cone ception of man as a biological entity-a mosaio built up from the bits and pieces gleaned from his specialist tuition. This perhaps explains the gulf which he has to bridge between medical school of hospital and successful general practice, for it is the latter which receives the first and major impact of psychosomatic implications. For the medical student and his tutor chapter three carries an important message.

The core of the work, the central i 5 chapters, are what the editor calls 'essays in clinical research." Their value to the reader lies not so much in the remarkable results which have been obtained, although many of these are important enough to deserve a place in the history of medical progress; rather does it lie in the unique practical demonstration it affords of psychosomatic theory. In this connection, too, the illustrations which accompany the text deserve special mention. The various research projects are described clearly and in such detail that no single book could hope to cover the whole field of medicine; what has been attempted here, with outstanding success, is the spotlighting of selected topics which throw into sharp relief some of the many facets of the body-mind relationship and yet at the same time illuminates the basic processes common to them all.

The whole work is a well-balanced exposition of the subject, and the closing three chapters bring in to prominence the techniques employed in the psychological treatment which supports, and in many cases dominates, the therapeutic programme. The reader is thus left completely satisfied-here are not only cause and effect, but cure too ! 